\title{
The effects of food stoichiometry and temperature on copepods are mediated by ontogeny
}

\author{
Lauren Mathews $^{1} \cdot$ Carolyn L. Faithfull $^{1,2,3}$ (D) Petra H. Lenz ${ }^{4} \cdot$ Craig E. Nelson $^{1}$
}

Received: 1 August 2017 / Accepted: 2 June 2018 / Published online: 13 June 2018

(c) The Author(s) 2018

\begin{abstract}
Climate change is warming the oceans, increasing carbon dioxide partial pressure and reducing nutrient recycling from deep layers. This will affect carbon $(\mathrm{C})$ and phosphorus $(\mathrm{P})$ availability in the oceans, thus, altering the balance between the nutrient content of consumers and their food resource. The combined effects of food quality and temperature have been investigated for adult copepods; however, nauplii, the early developmental stages of copepods, often far outnumber adults, grow more rapidly and have a higher phosphorus body content and demand than later life stages. Consequently, ontogeny may affect how copepods respond to the combined stressors of increasing temperature and altered food stoichiometry. We conducted temperature-controlled experiments $\left(24,28\right.$ and $\left.32{ }^{\circ} \mathrm{C}\right)$ where Parvocalanus crassirostris was fed either a P-replete or a P-limited phytoplankton food source. Reduced survival of nauplii and copepodites at the highest temperature was ameliorated when fed P-replete food. At higher temperatures, copepodite growth remained stable, but internal C:P stoichiometry diverged in the direction of phytoplankton $\mathrm{C}: \mathrm{P}$, suggesting that increased temperature affected copepodite stoichiometric homeostasis. In contrast, naupliar P content increased with temperature and naupliar growth was P limited, suggesting nauplii required additional phosphorus at higher temperatures. We conclude that resource stoichiometry plays a key role in how copepod survival and growth are impacted by temperature, and that ontogeny mediates these responses. Our results suggest that as the extent of warming oceans and phytoplankton nutrient limitation increase, copepod survival and the growth of early life stages may decline.
\end{abstract}

Keywords Nauplii $\cdot$ Warming $\cdot$ Food web $\cdot$ Metabolism $\cdot$ Zooplankton $\cdot$ Phosphorus

\section{Introduction}

Communicated by Maarten Boersma.

Electronic supplementary material The online version of this article (https://doi.org/10.1007/s00442-018-4183-6) contains supplementary material, which is available to authorized users.

Carolyn L. Faithfull

clfaithfull@gmail.com

1 Center for Microbial Oceanography: Research and Education, Department of Oceanography and Sea Grant College Program, University of Hawai'i at Mānoa, Honolulu, USA

2 Department of Ecology and Environmental Sciences, Umeå University, Umeå, Sweden

3 Gävleborg County Administrative Board, Gävle, Sweden

4 Pacific Biosciences Research Center, University of Hawai ‘ $i$ at Mānoa, Honolulu, USA
Climate change will challenge organisms to adapt to new environmental conditions. Warming of the earth's atmosphere and increased carbon dioxide availability are two trends we see today that may change the chemical composition and growth rates of autotrophs (Urabe et al. 2003; Riebesell et al. 2007; Toseland et al. 2013). In the ocean, warmer surface temperatures will lead to stronger stratification and decreased $\mathrm{P}$ recycling from the deep ocean, and increased partial pressure of carbon dioxide increases the availability of carbon relative to other nutrients (Riebesell et al. 2007; Thomas et al. 2013; Karl 2014). Phytoplankton chemical composition tends to be more flexible than their consumers' body stoichiometry and more closely reflects the availability of carbon and nutrients (Urabe et al. 2003; Klausmeier et al. 2004; Meunier et al. 2016). In contrast, consumers are generally more nutrient rich than phytoplankton, have rigid metabolic needs, and regulate key 
physiological processes such as uptake, incorporation, and release of elements, to adjust for the mismatch between their body stoichiometry and the elemental content of their food source (Elser et al. 2003; Brown et al. 2004; Frost et al. 2005; Riebesell et al. 2007). Therefore, climate change may challenge consumers to adapt to a future food resource that may not chemically reflect the food source they rely on today, or be outcompeted by species with optimized nutrient uptake affinities, storage and retention traits (Meunier et al. 2016).

Numerous animals undergo dramatic shifts in ecology over their life history, presumably to maximize growth, survival and reproduction of the organism over their life span. Warmer oceanic temperatures may affect timing and duration of consumer developmental stages, metabolic rates and nutrient demand. Copepods are an important phytoplankton consumer group (Taylor et al. 2012), which undergo a metamorphosis between the 6th nauplius and 1st copepodite stage, which includes rearrangement of appendages and nervous system, shifts in feeding behavior, nutrient demand and body stoichiometry (Paffenhöfer and Lewis 1989; Peterson 2001; Titelman and Kiørboe 2003; Wilson and Hartline 2011). Due to the abundance of copepods and especially nauplii in the ocean (Turner 2004), how copepod stages respond differentially to warming and changes in phytoplankton stoichiometry will have implications for nutrient cycling and food web dynamics (Frost et al. 2005; Riebesell et al. 2007).

Two main hypotheses describe how herbivore stoichiometry and nutrient demand should respond to temperature: (1) the growth rate hypothesis, and (2) the metabolic efficiency theory. The growth rate hypothesis argues that nutrient demand should increase with temperature due to higher growth rates and associated increased phosphorus demands for RNA and protein synthesis (Elser et al. 2003; Vrede et al. 2004). The metabolic efficiency theory argues that as temperature increases the efficiency of RNA and protein synthesis in biochemical reactions increases; therefore, higher growth rates can be maintained with fewer nutrients at higher temperatures (McFeeters and Frost 2011; Toseland et al. 2013). Recent studies have found that adult copepods seem to be less affected by nutrient limitation with increasing temperature, suggesting their nutrient use becomes more efficient at higher temperatures in accordance with the metabolic efficiency theory (Malzahn et al. 2016; Anderson et al. 2017). However, due to the dramatic physical and stoichiometric differences between nauplii and copepodite stages, ontogeny may influence zooplankton responses to temperature and food stoichiometry. For example, a recent study found that nauplii growth was more sensitive to food nutrient content than adult copepods (Bullejos et al. 2014). Our study addresses the interactive effects of food quality and temperature on the survival, growth, stoichiometry and grazing rate of both naupliar and copepodite stages of the widespread subtropical calanoid copepod species, Parvocalanus crassirostris.

Due to higher growth rates and the higher $\mathrm{P}$ demand of nauplii relative to copepodites (Elser et al. 2003; Bullejos et al. 2014; Meunier et al. 2016), we hypothesize that nauplii will follow the predictions of the growth rate hypothesis, with naupliar phosphorus demand increasing with warmer temperatures (Elser et al. 2003; Persson et al. 2011). As copepodites are slower growing and nearing reproduction, their survival may be maximized by adapting to higher temperatures and $\mathrm{P}$ limitation using phosphorus more efficiently according to the metabolic efficiency theory (Cross et al. 2015; Boersma et al. 2016). Because of the abundance and importance of $P$. crassirostris as a larval fish food source (Sampey et al. 2007; Kline and Laidley 2015), changes in the survival, growth, and stoichiometry of this copepod species with climate change may alter subtropical coastal food webs. This is the first time the contrasting predictions of the growth rate hypotheses and the metabolic efficiency theory have been tested in the same organism at different life history stages. Our results will lead to a better understanding of how ontogeny influences consumer phosphorus demand in response to warming.

\section{Materials and methods}

To investigate how temperature and food phosphorus $(\mathrm{P})$ content affect life history parameters (survival, growth rate, grazing rate and carbon:phosphorus stoichiometry) of the calanoid copepod $P$. crassirostris, we conducted three experiments at 25,28 , and $32{ }^{\circ} \mathrm{C}$ to simulate average winter $\left(24-25^{\circ} \mathrm{C}\right)$, summer $\left(26-28^{\circ} \mathrm{C}\right)$ and extreme summer sea surface temperatures in a tropical coastal environment (Jokiel and Brown 2004; Thomas et al. 2013). Experiments were based in Hawai'i and took place during 19-25 Nov 2015, 11-16 Mar 2016 and 14-20 Jan 2016 for the $25^{\circ} \mathrm{C}$, $28{ }^{\circ} \mathrm{C}$ and $32{ }^{\circ} \mathrm{C}$ experiments, respectively. In each experiment, $P$. crassirostris were fed Tisochrysis lutea cultures grown at two different nutrient stoichiometries (P replete and $\mathrm{P}$ limited) for 7 days, spanning one life cycle from nauplius to adult. For $P$. crassirostris, it takes approximately 3-4 days to reach the CI stage, and then another 3-4 days from CI to CVI. To capture the variation between naupliar and copepodite stages, each 7-day experiment was divided into two parts, where the first part (day 0-day 3) captured the life history information for nauplii $\left(\sim 2000\right.$ ind $\left.\mathrm{L}^{-1}\right)$, which were then sampled on day 3 , and rediluted to $500 \mathrm{~L}^{-1}$ for the second part of the experiment (day 4-day 7), which provided life history information for copepodites (Fig. 1). The timing of the two sampling occasions, the first after 3 days 


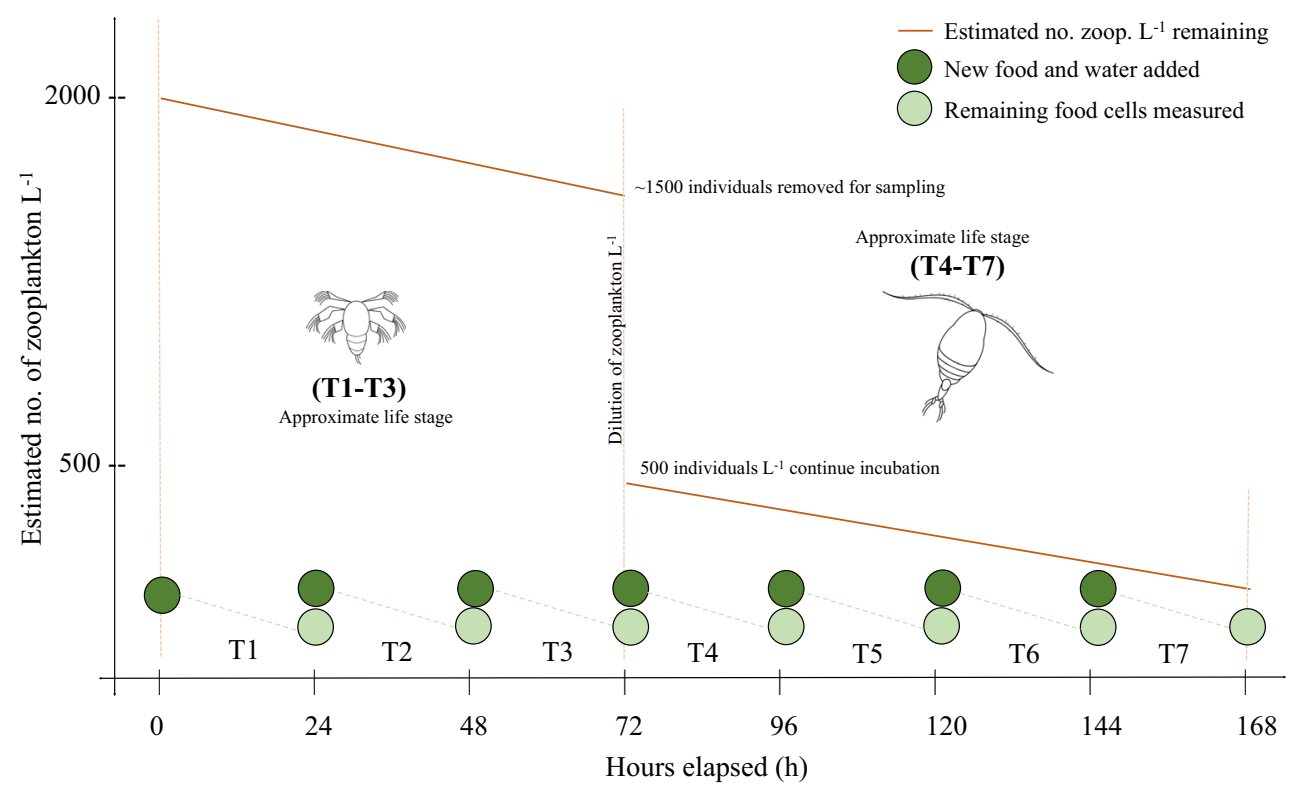

Fig. 1 Sampling regime schematic illustrating (1) when the nauplii (hour 0 and 72) and copepodites (hour 168) were collected for sampling and which measurements were taken, (2) the estimated number of zooplankton $\mathrm{L}^{-1}$ surviving through the 168-h (7 day) incubation

to capture the naupliar stages and the second after a further 4 days, ensured that a proportion of copepodites would reach adulthood, but there would not be much egg production.

\section{Phytoplankton culture}

For both cultures and experiments sub-surface seawater was collected from Kāne'ohe bay, O`ahu, Hawai 'i $\left(21^{\circ} 27^{\prime} 31.7^{\prime \prime} \mathrm{N}\right.$ $\left.157^{\circ} 48^{\prime} 03.5^{\prime \prime} \mathrm{W}\right)$ and filtered sequentially through glass fiber $(0.7 \mu \mathrm{m}$ pore size $\mathrm{GF} / \mathrm{F})$ and $0.1 \mu \mathrm{m}$ polycarbonate filters. The filtered seawater (FSW) was kept cool $\left(4^{\circ} \mathrm{C}\right)$ until $24 \mathrm{~h}$ before the start of each experiment when it was placed in an incubator at the experimental temperature (25, 28 , or $32{ }^{\circ} \mathrm{C}$ ). To create the two food treatments, $T$. lutea was cultured under two different nutrient and light conditions. For the P-replete treatment, T. lutea was cultured using P-replete f/2 medium (Andersen 2005) and a light level of $17.6 \pm 1.32 \mu \mathrm{mol} \mathrm{m}^{-2} \mathrm{~s}^{-1}$. For the P-limited culture, T. lutea was cultured in $\mathrm{f} / 2$ media without phosphate and at a higher light level $\left(60.1 \pm 3.36 \mu \mathrm{mol} \mathrm{m}^{-2} \mathrm{~s}^{-1}\right)$. The T. lutea cultures were incubated in batch culture in $6 \times 500-\mathrm{mL}$ sterile polycarbonate cell culture flasks, with one flask allocated to each day of the experiment. To control for potential variation in phytoplankton cultures over time, each flask was inoculated from an axenic T. lutea stock culture 2 weeks prior to its use during the experiment to allow the cultures to achieve a cell density above $9 \times 10^{5}$ cells $\mathrm{mL}^{-1}$, and to ensure that every day the copepods received fresh algae from a new bottle in the same growth phase (Fig. 1). C, N and P samples including the removal of approximately 1500 zooplankton $\mathrm{L}^{-1}$ at hour 72 which yielded a remaining 500 zooplankton $\mathrm{L}^{-1}$ in incubation bottles at the start of T4, and (3) the regimen of the complete replacement of food every $24 \mathrm{~h}$

from the phytoplankton cultures fed to the zooplankton were measured daily to control for any variation. All cultures were incubated at a 12:12, light:dark cycle at $25{ }^{\circ} \mathrm{C}$. P-replete cultures had an average C:P of 141:1 \pm 46 (mean \pm standard deviation), whereas P-limited cultures had an average $\mathrm{C}: \mathrm{P}$ of $1158 \pm 134$. Stoichiometry of the T. lutea fed to the zooplankton cultures over time is presented in Online Resource Fig. S2.

\section{Copepod culture}

Parvocalanus crassirostris stock cultures have been continuously maintained in $20-\mathrm{L}$ polycarbonate containers at room temperature (approximately $25-27^{\circ} \mathrm{C}$ ) at the Pacific Biosciences Research Center in the Lenz lab since 2008. To obtain a fresh cohort of nauplii for each experiment, we removed approximately 10,000 adults by filtering the source culture through a $162-\mu \mathrm{m}$ mesh filter and gently washing adults caught on the mesh into a separate $10 \mathrm{~L}$ (FSW) egg-laying culture $20 \mathrm{~h}$ before the start of each experiment. The adults were fed $40 \mathrm{~mL}$ of $T$. lutea (mean density of $9 \times 10^{5}$ cells $\mathrm{mL}^{-1}$ ) per $1 \mathrm{~L}$ of seawater to promote egg production. After $15 \mathrm{~h}$, adults were removed by filtering the egg-laying culture three times using a $162-\mu \mathrm{m}$ filter. The remaining culture contained only nauplii and eggs produced during the overnight egg-production incubation. Nauplii were then filtered onto a $20-\mu \mathrm{m}$ filter and washed into fresh FSW. This was repeated three times to obtain 
approximately 36,000 nauplii between the NI-NIII stages for each experiment.

\section{Experimental methods}

On day 0, 2000 NI-NIII nauplii (6-18 h old) were added to six of the twelve $1 \mathrm{~L}$ treatment bottles. Naupliar densities in the egg production containers were estimated by counting nauplii in three subsamples, and then adding the appropriate volume to achieve a population of 2000 animals per experimental bottle. Three bottles with nauplii and three bottles without nauplii received the P-limited T. lutea culture and the same for the P-replete T. lutea. After every $24 \mathrm{~h}$ period, the animals were transferred into fresh food suspensions. The daily dosage of food for both treatments was equivalent to $0.1 \mu \mathrm{g} \mathrm{C} \mathrm{L}^{-1} \mathrm{day}^{-1}$, which was found to be not limiting for $P$. crassirostris growth at the experimental densities in an earlier pilot study and by Böttjer et al. (2010). Culture density of T. lutea was determined by making triplicate cell counts using a double Neubauer counting chamber and viewed under a Leica compound microscope $(200 \times$ magnification). T. lutea culture cell counts were converted to carbon units using the method of Menden-Deuer and Lessard (2000):

$\log _{10} \mathrm{C}(\mathrm{pg})=-0.541+8.11 \times \log _{10}(V)$.

Additionally, two $20 \mathrm{~mL}$ subsamples from each $T$. lutea culture were filtered onto acid-washed $(1.5 \mathrm{M} \mathrm{HCl})$ and combusted $\left(510{ }^{\circ} \mathrm{C}, 4 \mathrm{~h}\right)$ glass fiber filters (Whatman, GF/F) and immediately frozen at $-20{ }^{\circ} \mathrm{C}$. One filter was used to measure particulate carbon $(\mathrm{C})$ and nitrogen $(\mathrm{N})$ and the other particulate phosphorus $(\mathrm{P})$.

Experimental bottles were incubated in the dark on a plankton roller for 7 days at the experimental temperature (experiment $1: 25^{\circ} \mathrm{C}$, experiment $2: 28^{\circ} \mathrm{C}$, and experiment 3: $32{ }^{\circ} \mathrm{C}$ ). After each $24 \mathrm{~h}$ period of incubation, each bottle was gently filtered through a $20 \mu \mathrm{m}$ filter, and the animals carefully transferred into an acid-washed $1 \mathrm{~L}$ polycarbonate bottle with FSW. After the appropriate food was added to each treatment bottle, bottles were returned to the dark incubator. From the filtrate remaining after the animals were removed, $4 \mathrm{~mL}$ was preserved for flow cytometric analysis with $200 \mu \mathrm{L}$ of $8 \%$ paraformaldehyde and frozen at $-80^{\circ} \mathrm{C}$ within 30 min of sampling, to determine remaining cell densities and calculate grazing rates.

Additional sampling to measure naupliar and copepodite survival, biomass and stoichiometry was conducted on day 0 , day 3 and day 7, respectively (Fig. 1). To measure naupliar survival from day 0 to day 3 and copepodite survival from day 3 to day 7 , animals from each bottle were concentrated to $100 \mathrm{~mL}$ and the numbers of individuals in five subsamples of $2 \mathrm{~mL}$ volumes were counted. On day 3, 500 individuals of the original 2000 animals from each replicate per treatment were transferred into a new treatment bottle and were incubated for the remaining four $24 \mathrm{~h}$ periods. The remaining animals (ca. 1500) were divided for biomass and stoichiometric measurements. On day 0 , day 3 and day 7 , 20-50 animals were first killed with $95 \%$ ethanol and then preserved in $70 \%$ ethanol for biomass measurements. Stoichiometry was measured on the remaining animals (from the treatment bottles on day 3 and day 7, and from the egg production culture on day 0 ), which were placed in FSW for approximately $2 \mathrm{~h}$ before being washed onto an $80 \mu \mathrm{m}$ mesh filter three times to remove food cells, and then onto a $20 \mu \mathrm{m}$ mesh filter, where they were first rinsed three times and then stored in Milli-Q water. Samples were frozen at $-80{ }^{\circ} \mathrm{C}$ for later analysis of particulate carbon, nitrogen and phosphorus.

To estimate biomass, we measured the stage and total length or prosome length, for nauplii and copepodites, respectively, at $60 \times$ magnification using a Leica light microscope. Lengths of each recorded developmental stage within a sample were averaged and an average dry weight in micrograms for each stage was calculated using the lifestage-specific length-dry weight regressions for $P$. crassirostris as in Hopcroft et al. (1998). These data were used to determine copepod stage distributions. Due to inconsistencies in dry weights obtained using the vacuum concentration method (see below for method), we were unable to derive a confident value for zooplankton dry weight. Consequently, to estimate carbon content we used dry weights obtained from length-dry weight regressions and converted to $\mathrm{C}$ content using a $\mathrm{C}$ dry weight ${ }^{-1}$ ratio of 0.45 (Omori and Ikeda 1984). The percentage of each stage counted and the survival data were used to calculate the average dry weight per individual for each treatment on day 0 , day 3 and day 7 . Specific growth rates $(G)$ were calculated from the average dry weights of individuals on day 0 , day 3 and day 7, using: $G=\ln \left(W_{t} / W_{0}\right) /_{t}$, where $W_{\mathrm{t}}$ is the weight at the end and $W_{0}$ is the weight at the beginning of time period $t$.

\section{Elemental analysis}

Before analysis of carbon and nitrogen, the zooplankton samples were vacuum concentrated (SAVANT ISS110, Thermo Scientific) and weighed in tin capsules. Samples of T. lutea preserved on glass fiber filters were dried at $60^{\circ} \mathrm{C}$, and packaged into tin capsules. All carbon and nitrogen measurements were made via high-temperature combustion on an Exeter Model CE 440 elemental analyzer at the SOEST laboratory for analytic biogeochemistry (University of Hawai'i at Mānoa). Particulate carbon and nitrogen standards were prepared using acetanilide $\left(\mathrm{C}_{8} \mathrm{H}_{9} \mathrm{NO}\right.$; molecular weight $=135.16$ ). For analysis of particulate phosphorus, the freeze-dried zooplankton samples were weighed, and zooplankton and filters were placed in individual acidwashed and pre-combusted glass combustion tubes, before 
combusting at $510{ }^{\circ} \mathrm{C}$ for $4 \mathrm{~h}$ to convert organic phosphorus to orthophosphate. For each sample, $10 \mathrm{~mL}$ of $0.15 \mathrm{M} \mathrm{HCl}$ was added, then vortexed and centrifuged before determination of the liberated orthophosphate by colorimetry following the procedure outlined in Strickland and Parsons (1972). Due to inconsistencies in dry weights obtained using the vacuum concentration method we were unable to calculate specific $\mathrm{C}, \mathrm{N}$ and $\mathrm{P}$ contents of zooplankton. Instead, here, we present molar ratios (e.g., $\mathrm{C}: \mathrm{P}$ ), which are independent of dry weight.

\section{Grazing rate}

To compare grazing rates among treatments, we quantified the number of live $T$. lutea cells remaining after each $24 \mathrm{~h}$ incubation using flow cytometry. Following thawing from $-80^{\circ} \mathrm{C}, 20 \mu \mathrm{L}$ of each sample was subsampled into a 96-well plate and stained with SYBR green $(1 \times$ final concentration). The plate was run on an Attune Flow cytometer, and T. lutea were categorized to be distinct populations of events characterized by high side scatter and forward scatter, high chlorophyll $a$ and high DNA (SYBR green) content. Events that satisfied all of four conditions were quantified into a concentration of event $\mu \mathrm{L}^{-1}$. Control treatment bottles were analyzed to account for changes in cell densities due to natural cell death or growth, and changes in cell counts in bottles without zooplankton for each food treatment were subtracted from each paired zooplankton bottle. Negative grazing rates were corrected to zero. Grazing rate was calculated as $T$. lutea cells consumed per $\mathrm{mg} \mathrm{C}$ of naupliar (day 0-day 3) or copepodite biomass (day 4-day 7) per day (cells $\mathrm{mg} \mathrm{C}^{-1} \mathrm{day}^{-1}$ ) (Moorthi et al. 2016). To estimate the number of zooplankton in each bottle at each time point we assumed that animal mortality occurred at a constant rate between the time points where animal density data were available (day 0 , day 3 , day 7 ).

\section{Statistical analyses}

Data were examined for normality and heteroscedasticity of variances using the Shapiro-Wilks test of normality, and then $\log _{10}$ transformed to meet model assumptions of normal distribution and heteroscedasticity of variances. We used two-way analysis of variance (ANOVA) with an interaction term to determine the responses of growth, average dry weight, and body stoichiometry to temperature, food treatment, and their interaction. Tukey's honestly significant differences were performed on all ANOVA results; to avoid clutter, only significant $P$ values and interactions are indicated in the graphs. To determine the effect of temperature and food treatment on daily grazing rates, we used repeated measures ANOVA, which was adjusted using covariance partitioning and model selection to account for the interdependence within bottles over time according to the methods outlined in Zuur et al. (2009), using the nlme package (Pinheiro et al. 2017). Survival data were analyzed as percentage survival using a linear model fitted with generalized least squares. An autoregressive correlation structure was used to describe the within-group correlation structure. This correlation structure was determined following the methods outlined in Zuur et al. (2009), by comparing different correlation structures using the Akaike and Bayesian information criterions and log likelihood to find the simplest model which best fit the data. To determine if stage distributions differed with temperature and food treatment, we used a paired Kolmogorov-Smirnov non-parametric test. All statistical analyses were performed using the R Statistical Programme (3.3.1).

\section{Results}

Temperature had the greatest effect on survival, with both nauplius and copepodite survival decreasing with temperature. Average survival was higher for nauplii (mean \pm standard error: $88 \pm 4 \%$ ) over the first 3 days, than for copepodites, $67 \pm 10 \%$, over the latter 4 days of each experiment. For nauplii, survival was $19 \%$ lower at $32{ }^{\circ} \mathrm{C}$ than at $25^{\circ} \mathrm{C}$ (Fig. 2a). Copepodite survival was also highest at $25^{\circ} \mathrm{C}$, being twice as high compared with survival at 28 or $32^{\circ} \mathrm{C}$ (Fig. 2b). The C:P ratio of P-limited food $(1158 \pm 134)$ was eight times higher than P-replete food $(141 \pm 46)$. Stoichiometry of the T. lutea fed to the zooplankton cultures over time is presented in Supplementary Information Fig. S2. The P content of the food did not affect nauplii or copepodite survival at 25 or $28{ }^{\circ} \mathrm{C}$. However, at $32{ }^{\circ} \mathrm{C}$ when fed P-replete food, nauplii survival was $15 \%$ higher and copepodite survival increased by $23 \%$ compared with those fed P-limited food.

Both nauplii and copepodites were heavier when fed P-replete food. Naupliar-specific dry weight was 37\% higher when fed P-replete food than P-limited food, and nauplii were $30 \%$ heavier at $25{ }^{\circ} \mathrm{C}$ than at $28{ }^{\circ} \mathrm{C}$ or $32{ }^{\circ} \mathrm{C}$ $\left(F_{2,12}=16.9, P=0.001\right)$. Copepodites fed P-rich food had $25 \%$ higher specific dry weight across all three temperatures $\left(F_{2,12}=12.6, P=0.004\right)$. There was a borderline effect of temperature on copepod biomass with copepodites at $32{ }^{\circ} \mathrm{C}$ being $24 \%$ heavier than copepodites at $28^{\circ} \mathrm{C}\left(F_{2,12}=3.83\right.$, $P=0.052$ ). There was no significant interaction between the effects of temperature and food treatment on nauplius or copepodite average specific dry weight.

The average specific grazing rate for nauplii was $248 \pm 81$ (mean $\pm \mathrm{SE}$ ) cells of $T$. lutea zooplankton $\mathrm{mg} \mathrm{C}^{-1} \mathrm{~h}^{-1}$. Grazing rates for copepodites averaged $93 \pm 12$ cells of $T$. lutea zooplankton $\mathrm{mg} \mathrm{C}^{-1} \mathrm{~h}^{-1}$. Grazing rates were below detection rates (i.e., zero) at $40 \%$ of sampling occasions for nauplii and $24 \%$ of sample occasions for copepods. Phytoplankton 


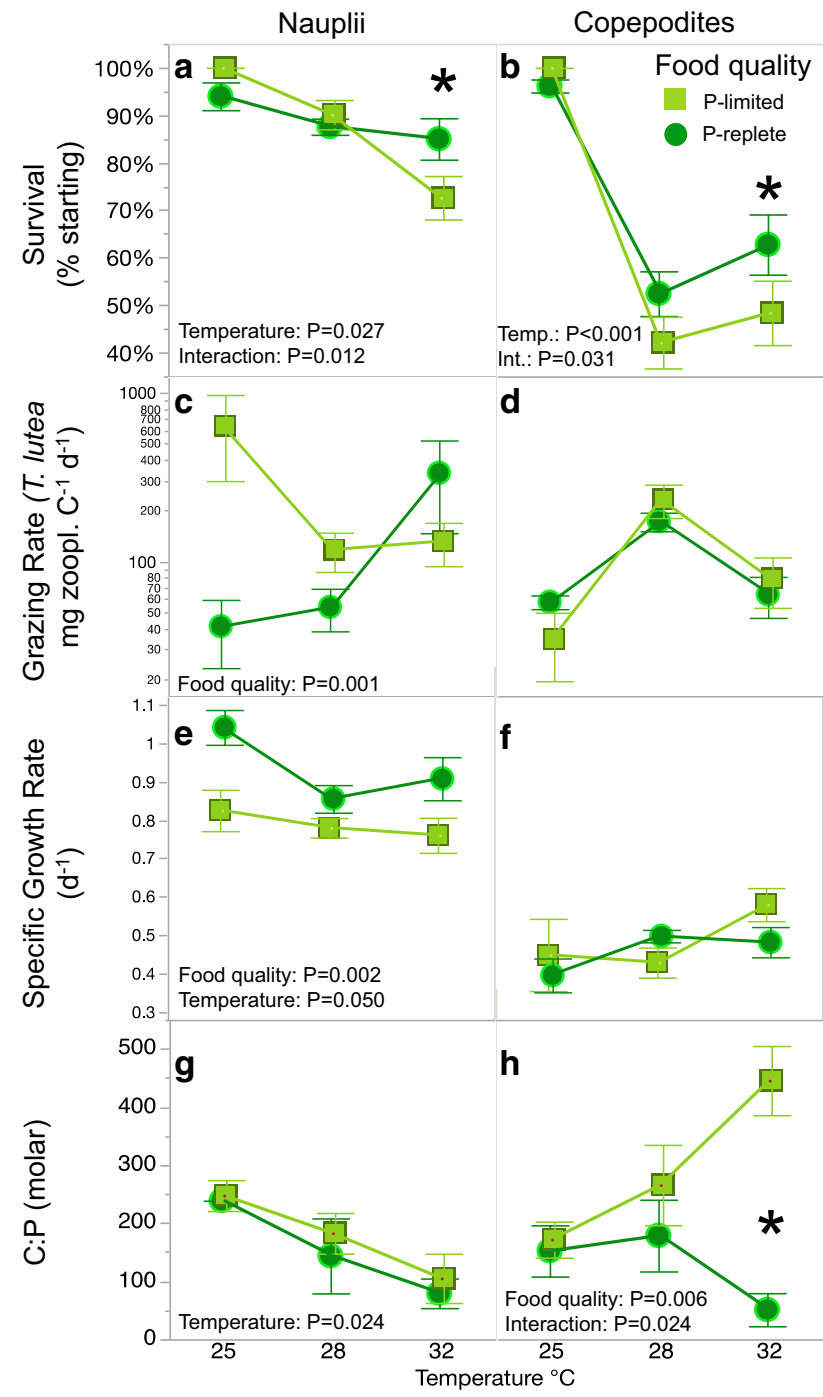

Fig. 2 Life history traits of the copepod P. crassirostris after 3 days (nauplii, left column) and 7 days (copepodites, right column) when fed P-limited (light) and P-replete (dark) phytoplankton at each of the three incubation temperatures: 25,28 , and $32{ }^{\circ} \mathrm{C}$. All values are mean \pm 1 standard error of the mean of three replicate incubation bottles $(N=3)$. Each panel is annotated with significant $P$ values from two-way ANOVA. Significant post hoc interactions between food quality at specific temperatures are represented by $*$. a, b The percentage of copepods surviving; c, $\mathbf{d}$ the specific copepod grazing rate (cells of Tisochrysis lutea zooplankton $\mathrm{mg} \mathrm{C}^{-1} \mathrm{~h}^{-1}$ );, $\mathbf{f}$ the specific growth rate $\left(\right.$ day $\left.^{-1}\right) ; \mathbf{g}, \mathbf{h}$ are the internal body stoichiometry of carbon:phosphorus (molar) for nauplii and copepodites, respectively

stoichiometry had a significant effect on naupliar grazing rate, where nauplii fed P-limited phytoplankton had 18 times as high grazing rates than nauplii fed P-replete food (Fig. 2c). Copepodite grazing rate did not change with food stoichiometry or temperature (Fig. 2d).

The average specific growth rate for nauplii was $0.86 \pm 0.11 \mathrm{~d}^{-1}$ and was affected by food quality and temperature. Naupliar-specific growth rate was nearly $20 \%$ higher when nauplii were fed P-rich food. In addition, naupliarspecific growth rates were highest at $25{ }^{\circ} \mathrm{C}$ (Fig. 2e). There was no interaction between temperature and food treatment on naupliar growth rate. The average specific growth rate for copepodites was $0.47 \pm 0.10 \mathrm{~d}^{-1}$. Copepodite growth rates did not differ with food $\mathrm{P}$ content and did not differ significantly with temperature (Fig. 2f).

Naupliar internal C:P and C:N were on average lower than copepodite internal stoichiometry, except at $25{ }^{\circ} \mathrm{C}$ where naupliar and copepodite stoichiometry did not differ significantly. Naupliar internal C:P averaged $189 \pm 8.72$ (mean \pm SE) and C:N 10.1 \pm 1.07 . Temperature had a negative effect on naupliar C:P (Fig. $2 \mathrm{~g}$ ). This was due to the $\mathrm{P}$ content of nauplii increasing with warmer temperatures $\left(F_{2,12}=4.47, P=0.035\right)$, while naupliar internal $\mathrm{C}$ concentrations did not change with temperature $\left(F_{2,12}=0.729\right.$, $P=0.503$ ). Elemental content of nauplii did not change with food quality; however, food quality had a large effect on copepodite stoichiometry. Average copepodite C:P was $242 \pm 11.3($ mean \pm SE) and copepodite $\mathrm{C}: \mathrm{N}$ was $17.0 \pm 3.11$. Differences in copepod stoichiometry were due to changes in $\mathrm{P}$ with food treatment and changes in $\mathrm{C}$ content were not significant. Copepod internal C:P did not differ with temperature alone, instead the effect of the different food treatments on copepodite internal C:P interacted with temperature. At $25{ }^{\circ} \mathrm{C}$, copepodites maintained a steady $\mathrm{C}: \mathrm{P}$ ratio regardless of food $\mathrm{P}$ content. In contrast, at $32{ }^{\circ} \mathrm{C}$, copepodite body $\mathrm{C}: \mathrm{P}$ diverged with $\mathrm{P}$ content of the food, and was nearly 11 times higher when fed the P-limited than when fed P-replete phytoplankton (Fig. 2h).

\section{Discussion}

The role of ontogeny in influencing fundamental life history traits is a central tenant of biology, and these experiments sought to investigate the influence of ontogeny on how the phosphorus requirement of naupliar and copepodite stages changes with increasing temperature. During development, copepods undergo a major transformation between the naupliar and copepodite stages. Between the last nauplius (NVI) and the first copepodite (CI) stage there is high mortality (Peterson 2001) associated with major morphological modifications, which include changes in swimming and feeding behavior, changes in the sensory system, and a reorganization of the nervous system (Paffenhöfer and Lewis 1989; Peterson 2001; Wilson and Hartline 2011). These changes have stoichiometric implications: body carbon-specific ingestion rates of nauplii are high and typically exceed $100 \%$ of body C per day (Meyer et al. 2002; Henriksen et al. 2007; Jungbluth et al. 2017), while those of adult copepods are below $30 \%$ of body C per day (Meyer 
et al. 2002). Furthermore, $\mathrm{C}: \mathrm{N}$ ratios are lower in nauplii than copepodites (Campbell et al. 2001). Thus, the growth requirements for nauplii differ from those of copepodites, which in turn could lead to higher physiological sensitivity to low nutrients as has been reported in previous work (Bullejos et al. 2014).

We hypothesized that nauplii would follow the predictions of the growth rate hypothesis, with naupliar phosphorus demand increasing with warmer temperatures, as found for freshwater zooplankton by Persson et al. (2011) and Wojewodzic et al. (2011). With increasing temperature, nauplii became more $\mathrm{P}$ rich, naupliar grazing rate on $\mathrm{P}$-rich food increased, and naupliar survival was higher when fed P-replete food, all findings are consistent with the growth rate hypothesis (Elser et al. 2003). In contrast, we hypothesized that as copepodites have lower specific growth rates and are nearing reproduction, their survival may be maximized by using phosphorus more efficiently according to the metabolic efficiency theory (McFeeters and Frost 2011; Cross et al. 2015). We found patterns that support the metabolic efficiency theory for copepodites, whereby when copepodites were fed high-C:P food, growth was not $\mathrm{P}$ limited at the highest temperature and copepodite $\mathrm{C}: \mathrm{P}$ increased with temperature. However, it should be noted that phosphorus rich food increased copepod survival at the highest temperature-which disagrees with the metabolic efficiency theory. Thus, it appears that these two competing models of nutrient limitation may apply to some degree in the same organism at different stages of their lifecycle. Below we discuss how ontogeny may mediate the effects of food stoichiometry and temperature on $P$. crassirostris survival, grazing, growth and $\mathrm{C}: \mathrm{P}$ stoichiometry.

Survival of nauplii and copepodites was negatively affected by higher temperatures. 25 and $28{ }^{\circ} \mathrm{C}$ are well within the natural range experienced by $P$. crassirostris in coastal Hawaiian ecosystems (Bahr et al. 2015). However, $32{ }^{\circ} \mathrm{C}$ is $3{ }^{\circ} \mathrm{C}$ higher than the average summer surface temperature, but close to the maximum observed coastal summer temperatures in Hawai' $i$ (Thomas et al. 2013), and approximates local thermal maxima during recent bleaching events in Kāne'ohe Bay (Bahr et al. 2015). We found that the number of nauplii and copepodites each bottle could support declined with increasing temperature. In accordance with the growth rate hypothesis, Brown et al. (2004) argued that as temperatures rise the number of individuals a specific environment can support will decline, as the same number of individuals will recycle carbon and nutrients at a higher rate. For this relationship to hold, there must be a limited amount of resources available and carbon or nutrients must limit growth at higher temperatures. The food concentrations used in this experiment were not found to be limiting for $P$. crassirostris in an earlier pilot study or by Böttjer et al. (2010). Although neither of these studies tested food limitation at $32{ }^{\circ} \mathrm{C}$, there were still phytoplankton cells left in the bottles after $24 \mathrm{~h}$, and it is unlikely that $\mathrm{C}$ limited growth at $32{ }^{\circ} \mathrm{C}$, as survival was higher when fed P-replete food at $32{ }^{\circ} \mathrm{C}$. Indeed, we found that when resources were higher in terms of nutrient availability, as in the P-replete treatments, both nauplii and copepodites had higher survival rates at $32{ }^{\circ} \mathrm{C}$. This suggests that higher phosphorus availability partly reduced the extra stress placed on the organisms by warmer temperatures. Lower survival at higher temperatures could also be due to faster developmental times and, therefore, earlier mortality (Rhyne et al. 2009; Malzahn et al. 2016). In our experiment, individuals did not age faster in warmer temperatures or in the P-replete treatments; therefore, the effects of temperature and food quality on survival and growth rates were not due to changes in developmental times or population distributions (Online Resource, Fig. S1).

We predicted that copepodite and naupliar stages would respond differently to temperature and phosphorus availability. Naupliar growth rate was higher with P-replete food across all temperatures and copepodite growth was not dependent on food P content. Sensitivity to nutrient mineral constraints may decrease with ontogeny in copepods, with nauplii having lower $C$ :nutrient ratios than adult copepods and being more prone to nutrient limitation than older stages (Laspoumaderes et al. 2010; Bullejos et al. 2014). In our study, naupliar $\mathrm{C}: \mathrm{P}$ ratios were not consistently lower than those of copepodites; however, we found that naupliar $\mathrm{C}: \mathrm{P}$ internal stoichiometry did not change with the $\mathrm{C}: \mathrm{P}$ content of their food, whereas copepodite internal stoichiometry reflected their food source at higher temperatures. Instead, nauplii became more phosphorus rich at higher temperatures, suggesting that naupliar phosphorus use did not become more efficient with warming. This is thought to be due to nauplii having higher specific growth rates and, therefore, higher phosphorus demands for ribosome and RNA production (Elser et al. 2003; Vrede et al. 2004; Meunier et al. 2016). With rising ocean temperatures, nauplii are likely to become even more phosphorus limited since their body phosphorus requirement will increase.

For copepodites, there was a decoupling of growth and survival in our study: phosphorus availability enhanced survival at higher temperatures but did not increase copepodite growth rates. If copepods need greater amounts of phosphorus at higher temperatures to cope with increased RNA and phosphorus demands (i.e., Elser et al. 2003; Persson et al. 2011), we would expect growth rates to be highest in the P-replete treatment when temperature is highest. Instead, we found copepodite growth rate at $32{ }^{\circ} \mathrm{C}$ was similar in both low and high $\mathrm{C}: \mathrm{P}$ treatments. At higher temperatures, copepods may require more carbon to cope with higher metabolic demands due to increased respiration relative to growth (Boersma et al. 2016; Malzahn et al. 2016). Thus, the patterns of copepodite growth in our experiment follow the 
metabolic efficiency theory; copepodite growth was uncorrelated with the $\mathrm{C}: \mathrm{P}$ ratio of phytoplankton across all temperatures (Fig. S3), and growth was higher at $32{ }^{\circ} \mathrm{C}$ when more carbon was available relative to phosphorus (Cross et al. 2015; Boersma et al. 2016). Consistent with the metabolic efficiency theory, copepodite body C:P increasingly diverged to reflect the food source (either P-replete or P-limited) as temperature increased.

Past studies suggest that the nitrogen and phosphorus content of organisms generally declines with increasing temperature (Rhee and Gotham 1981; Woods et al. 2003). The larger size and slower relative growth of copepodites may have enabled them to reallocate elements and have a more flexible body stoichiometry than nauplii. As temperature increases, the efficiency of RNA and protein use in biochemical reactions increases and the quantity of proteins needed for growth decreases according to the metabolic efficiency theory (McFeeters and Frost 2011; Toseland et al. 2013). Copepodite growth rates did not differ with food quality at $32{ }^{\circ} \mathrm{C}$, even as internal $\mathrm{C}: \mathrm{P}$ stoichiometry increased when fed P-limited food; therefore, it appears that copepodites used phosphorus more efficiently at higher temperatures (Woods et al. 2003; McFeeters and Frost 2011; Cross et al. 2015).

To obtain nutrients required for growth and development, zooplankton can select higher quality food (selective grazing), or graze at higher rates on low-quality food (compensatory grazing) (Hillebrand et al. 2009; Meunier et al. 2016). In our experiment, naupliar grazing rates were highest when fed P-limited food across all temperatures, which may be a compensatory mechanism to obtain the phosphorus required for growth, while respiring or excreting the excess carbon (Hillebrand et al. 2009). In our experiment, naupliar growth was $\mathrm{P}$ limited across all temperatures, which suggests that nauplii were unable to completely compensate for lower food quality by increasing their grazing rate on P-limited food (Moorthi et al. 2016). Copepodites did not exhibit compensatory grazing, which may reflect their lower nutrient demand (Bullejos et al. 2014; Meunier et al. 2016). Copepodite grazing rate did not increase with temperature (Brown et al. 2004; Hillebrand et al. 2009; Moorthi et al. 2016). Instead copepodites had the highest grazing rates at $28^{\circ} \mathrm{C}$, which represents summer sea surface temperatures in coastal Hawai'i waters (Bahr et al. 2015). The lower survival and reduced homeostasis of copepodite internal stoichiometry at $32{ }^{\circ} \mathrm{C}$ suggest that this temperature is outside the optimal environmental range for $P$. crassirostris in Hawai'i.

There was no significant effect of temperature on zooplankton biomass in either ontogenetic stage. The lack of temperature effect on naupliar- and copepodite-specific body mass emphasizes that temperature has a greater effect on more dynamic life history parameters such as survival and grazing rates, while zooplankton maintain a stable mass dictated largely by their available nutrient resources. This was evident in the positive effect that P-replete food had on both naupliar and copepodite individual biomass. Decreased nutrient availability may result in reduced metazoan body sizes due to suboptimal protein synthesis, which is linked to growth rate and development (Sterner 1993; Elser et al. 2003; Cross et al. 2015). Characteristics of nauplii, such as high growth rates, high phosphorus demand and small body size, may have contributed to increasing phosphorus requirements at warmer temperatures according to the predictions of the growth rate hypothesis. In contrast, copepodite phosphorus demand appeared to decline with warming, in accordance with the metabolic efficiency theory; however, copepodite survival was still positively affected by phosphorus availability at extreme temperatures. These results, although only for a single species, illustrate that ontogeny has important implications for carbon and phosphorus demand with temperature. Young fast-growing stages may depend more on limiting nutrients (Bullejos et al. 2014) than slower growing older stages, which have greater nutrient reserves to draw upon when exposed to stressful nutrient-limiting conditions. Further investigation into the cellular mechanisms behind why adult copepods and not nauplii are able to employ more efficient use of phosphorus at higher temperatures may reveal important metabolic insights as to why organisms exhibit ontogenetic shifts.

Due to the abundance and relatively high grazing impacts of nauplii (Jungbluth et al. 2017), nauplii may have a different and significant influence on carbon and nutrient cycling compared to adult and copepodite stages. Due to the decreasing C:P stoichiometry and increasing phosphorus demand of nauplii with rising temperature, it is possible that abundant nauplii may reduce phosphorus recycling in an already $\mathrm{P}$-limited ocean. Copepodites, on the other hand, are unlikely to alter $\mathrm{P}$ recycling in a warming ocean due to their flexible $\mathrm{C}: \mathrm{P}$ body stoichiometry and lower phosphorus demand. Future investigation is still needed to understand how copepods will affect nutrient cycling of other important elements, such as nitrogen (e.g., Meunier et al. 2016), over their lifecycles, and the feedbacks this will have on copepod population dynamics and ocean elemental cycling remain to be studied.

Acknowledgements We would like to thank the Nelson and Alegado lab groups for helpful discussions and suggestions, Justin Suitos and Yuuki Niimi for maintaining and preparing P. crassirostris cultures. Funding was provided by University of Hawai 'i Space Grant Consortium and the University of Hawai' $i$ at Mānoa Undergraduate Research Opportunities Program to L. Mathews. The project was also supported by the Vetenskapsrådet Grant 637-2013-7449 to C. Faithfull, the National Science Foundation Grants OCE 1235549 (PIs: P. Lenz and D. Hartline), OCE 1255697 (PIs: E. Goetze, K. Selph and P. Lenz) and OCE-1538393 (PI: C. Nelson). C.E.N. was funded in part by a grant/ cooperative agreement from the National Oceanic and Atmospheric 
Administration, Project A/AS-1, which is sponsored by the University of Hawai'i Sea Grant College Program under Institutional Grant no. NA14OAR4170071 from NOAA Office of Sea Grant, Department of Commerce. The views expressed herein are those of the authors and do not necessarily reflect the views of NOAA or any of its subagencies. This manuscript is University of Hawai'i at Mānoa School of Ocean and Earth Science and Technology publication no. 10369 and UH Sea Grant publication number UNIHI-SEAGRANT-JC-17-12.

Author contribution statement LM and CLF conceived and designed the experiments. LM and CLF performed the experiments. PHL supplied the experimental organisms. LM, CLF and CEN analyzed the samples and data. LM and CLF wrote the manuscript. PHL and CEN provided statistical advice and edited the manuscript.

Open Access This article is distributed under the terms of the Creative Commons Attribution 4.0 International License (http://creativeco mmons.org/licenses/by/4.0/), which permits unrestricted use, distribution, and reproduction in any medium, provided you give appropriate credit to the original author(s) and the source, provide a link to the Creative Commons license, and indicate if changes were made.

\section{References}

Andersen RA (ed) (2005) Algal culturing techniques. Elsevier, New York

Anderson TR, Hessen DO, Boersma M, Urabe J, Mayor DJ (2017) Will invertebrates require increasingly carbon-rich food in a warming world? Am Nat 190:725-742. https://doi.org/10.1086/694122

Bahr KD, Jokiel PL, Rodgers KS (2015) The 2014 coral bleaching and freshwater flood events in Kāne'ohe Bay, Hawai' $i$. PeerJ 3:e1136

Boersma M, Mathew KA, Niehoff B, Schoo KL, Franco-Santos RM, Meunier CL (2016) Temperature driven changes in the diet preference of omnivorous copepods: no more meat when it's hot? Ecol Lett 19:45-53. https://doi.org/10.1111/ele.12541

Böttjer D, Morales CE, Bathmann U (2010) Trophic role of small cyclopoid copepod nauplii in the microbial food web: a case study in the coastal upwelling system off central Chile. Mar Biol 157:689-705. https://doi.org/10.1007/s00227-009-1353-4

Brown JH, Gillooly JF, Allen AP, Savage VM, West GB (2004) Toward a metabolic theory of ecology. Ecology 85:1771-1789. https://doi. org/10.1890/03-9000

Bullejos FJ, Carrillo P, Gorokhova E, Medina-Sanchez JM, Balseiro EG, Villar-Argaiz M (2014) Shifts in food quality for herbivorous consumer growth: multiple golden means in the life history. Ecology 95:1272-1284

Campbell RG, Wagner MM, Teegarden GJ et al (2001) Growth and development rates of the copepod Calanus finmarchicus reared in the laboratory. Mar Ecol Prog Ser 221:161-183

Cross WF, Hood JM, Benstead JP, Huryn AD, Nelson D (2015) Interactions between temperature and nutrients across levels of ecological organization. Glob Change Biol 21:1025-1040. https:// doi.org/10.1111/gcb.12809

Elser JJ, Acharya K, Kyle M, Cotner J, Makino W, Markow T, Watts T, Hobbie S, Fagan W, Schade J, Hood J, Sterner RW (2003) Growth rate-stoichiometry couplings in diverse biota. Ecol Lett 6:936-943. https://doi.org/10.1046/j.1461-0248.2003.00518.x

Frost PC, Evans-White MA, Finkel ZV, Jensen TC, Matzek V (2005) Are you what you eat? Physiological constraints on organismal stoichiometry in an elementally imbalanced world. Oikos 109:1828. https://doi.org/10.1111/j.0030-1299.2005.14049.x

Henriksen C, Saiz E, Calbet A, Hansen B (2007) Feeding activity and swimming patterns of Acartia grani and Oithona davisae nauplii in the presence of motile and non-motile prey. Mar Ecol Prog Ser 331:119-129

Hillebrand H, Borer ET, Bracken MES, Cardinale BJ, Cebrian J, Cleland EE, Elser JJ, Gruner DS, Stanley Harpole W, Ngai JT, Sandin S, Seabloom EW, Shurin JB, Smith JE, Smith MD (2009) Herbivore metabolism and stoichiometry each constrain herbivory at different organizational scales across ecosystems. Ecol Lett 12:516-527. https://doi.org/10.1111/j.1461-0248.2009.01304.x

Hopcroft RR, Roff JC, Lombard D (1998) Production of tropical copepods in Kingston Harbour, Jamaica: the importance of small species. Mar Biol 130:593-604. https://doi.org/10.1007/s002270050 281

Jokiel PL, Brown EK (2004) Global warming, regional trends and inshore environmental conditions influence coral bleaching in Hawaii. Glob Change Biol 10:1627-1641. https://doi.org/10.11 11/j.1365-2486.2004.00836.x

Jungbluth MJ, Selph KE, Lenz PH, Goetze E (2017) Incubation duration effects on copepod naupliar grazing estimates. J Exp Mar Biol Ecol 494:54-62

Karl DM (2014) Microbially mediated transformations of phosphorus in the sea: new views of an old cycle. Annu Rev Mar Sci 6:279-337

Klausmeier CA, Litchman E, Levin SA (2004) Phytoplankton growth and stoichiometry under multiple nutrient limitation. Limnol Oceanogr 49:1463-1470

Kline MD, Laidley CW (2015) Development of intensive copepod culture technology for Parvocalanus crassirostris: optimizing adult density. Aquaculture 435:128-136

Laspoumaderes C, Modenutti B, Balseiro E (2010) Herbivory versus omnivory: linking homeostasis and elemental imbalance in copepod development. J Plankton Res 32:1573-1582

Malzahn AM, Doerfler D, Maarten B (2016) Junk food gets healthier when it's warm. Limnol Oceanogr 61:1677-1685. https://doi. org/10.1002/lno.10330

McFeeters BJ, Frost PC (2011) Temperature and the effects of elemental food quality on Daphnia. Freshw Biol 56:1447-1455

Menden-Deuer S, Lessard EJ (2000) Carbon to volume relationships for dinoflagellates, diatoms, and other protist plankton. Limnol Oceanogr 45:569-579

Meunier CL, Boersma M, Wiltshire KH, Malzahn AM (2016) Zooplankton eat what they need: copepod selective feeding and potential consequences for marine systems. Oikos 125:50-58

Meyer B, Irigoien X, Graeve M, Head R, Harris R (2002) Feeding rates and selectivity among nauplii, copepodites and adult females of Calanus finmarchicus and Calanus helgolandicus. Helgol Mar Res 56:169-176

Moorthi SD, Schmitt JA, Ryabov A, Tsakalakis I, Blasius B, Prelle L, Tiedemann M, Hodapp D (2016) Unifying ecological stoichiometry and metabolic theory to predict production and trophic transfer in a marine planktonic food web. Philos Trans R Soc B. https://doi.org/10.1098/rstb.2015.0270

Omori M, Ikeda T (1984) Methods in marine zooplankton ecology. Wiley, New York

Paffenhöfer G, Lewis KD (1989) Feeding behaviour of nauplii of the genus Eucalanus (Copepoda, Calanoida). Mar Ecol Prog Ser 57:129-136

Persson J, Wojewodzic MW, Hessen DO, Andersen T (2011) Increased risk of phosphorus limitation at higher temperatures for Daphnia magna. Oecologia 165:123-129

Peterson WT (2001) Patterns in stage duration and development among marine and freshwater calanoid and cyclopoid copepods: a review 
of rules, physiological constraints, and evolutionary significance. Hydrobiologia 453:91-105

Pinheiro J, Bates D, DebRoy S, Sarkar D (2017) nlme: linear and nonlinear mixed effects models, $\mathrm{R}$ package version 3.1-131

Rhee G, Gotham IJ (1981) The effect of environmental factors on phytoplankton growth: temperature and the interactions of temperature with nutrient limitation. Limnol Oceanogr 26:635-648

Rhyne AL, Ohs CL, Stenn E (2009) Effects of temperature on reproduction and survival of the calanoid copepod Pseudodiaptomus pelagicus. Aquaculture 292:53-59

Riebesell U, Schulz KG, Bellerby RGJ, Botros M, Fritsche P, Meyerhofer M, Neill C, Nondal G, Oschlies A, Wohlers J, Zollner E (2007) Enhanced biological carbon consumption in a high $\mathrm{CO}_{2}$ ocean. Nature 450:545-548

Sampey A, McKinnon AD, Meekan MG, McCormick MI (2007) Glimpse into guts: overview of the feeding of larvae of tropical shorefishes. Mar Ecol Prog Ser 339:243-257

Sterner RW (1993) Daphnia growth on varying quality of Scenedesmus - mineral limitation of zooplankton. Ecology 74:2351-2360

Strickland JDH, Parsons TR (1972) A practical handbook of seawater analysis. Fisheries Research Board of Canada, Ottawa

Taylor GT, Muller-Karger FE, Thunell RC, Scranton MI, Astor Y, Varela R, Ghinaglia LT, Lorenzoni L, Fanning KA, Hameed S, Doherty O (2012) Ecosystem responses in the southern Caribbean Sea to global climate change. Proc Natl Acad Sci USA 109:19315-19320. https://doi.org/10.1073/pnas.1207514109

Thomas J, University of California-San Diego, Scripps Institution of Oceanography (2013) Documentation for Scripps Institution of Oceanography (SIO) coastal data information program (CDIP) data archived at NODC (NODC Accession 0104062). Version
1.1. National Oceanographic Data Center, NOAA. Dataset. 2016-10-11

Titelman J, Kiørboe T (2003) Motility of copepod nauplii and implications for food encounter. Mar Ecol Prog Ser 247:123-135

Toseland A, Daines SJ, Clark JR, Kirkham A, Strauss J, Uhlig C, Lenton TM, Valentin K, Pearson GA, Moulton V, Mock T (2013) The impact of temperature on marine phytoplankton resource allocation and metabolism. Nat Clim Change 3:979-984. https://doi. org/10.1038/nclimate1989

Turner JT (2004) The importance of small planktonic copepods and their roles in pelagic marine food webs. Zoolog Stud 43:255-266

Urabe J, Togari J, Elser JJ (2003) Stoichiometric impacts of increased carbon dioxide on a planktonic herbivore. Glob Change Ecol 9:818-825. https://doi.org/10.1046/j.1365-2486.2003.00634.x

Vrede T, Dobberfuhl DR, Kooijman S, Elser JJ (2004) Fundamental connections among organism C:N:P stoichiometry, macromolecular composition, and growth. Ecology 85:1217-1229

Wilson CH, Hartline DK (2011) Novel organization and development of copepod myelin. ii. Nonglial origin. J Comp Neurol 519:32593280. https://doi.org/10.1002/cne.22695

Wojewodzic MW, Rachamim T, Andersen T, Leinaas HP, Hessen DO (2011) Effect of temperature and dietary elemental composition on RNA/protein ratio in a rotifer. Funct Ecol 25:1154-1160. https ://doi.org/10.1111/j.1365-2435.2011.01864.x

Woods H, Makino W, Cotner J, Hobbie S, Harrison J, Acharya K, Elser J (2003) Temperature and the chemical composition of poikilothermic organisms. Funct Ecol 17:237-245

Zuur A, Ieno EN, Walker N, Saveliev AA, Smith GM (2009) Mixed effects models and extensions in ecology with R. Springer, New York 